\title{
Cytological evaluation of breast lesions with histopathological correlation in patients present with breast lump
}

\author{
Patel F.T. ${ }^{1}$, Shah B.A. ${ }^{2}$, Parikh N.R. ${ }^{3}$, Gonsai R.N. ${ }^{4}$ \\ ${ }^{1}$ Dr. Falguni T. Patel, Associate Professor, ${ }^{2}$ Dr. Bhoomi A. Shah, Tutor, ${ }^{3}$ Dr. Nisarg R. Parikh, Professor, ${ }^{4}$ Dr. Ratigar N. \\ Gonsai, Head \& Professor, all authors are affiliated with Department of Pathology, Dr. M. K. Shah Medical College and \\ Research Centre, Chandkheda, Ahmedabad, Gujarat, India.
}

Corresponding Author: Dr. Bhoomi A. Shah, Tutor, Department of Pathology, Dr. M. K. Shah Medical College and Research Centre, Chandkheda, Ahmedabad, Gujarat, India. E-mail: bhoomigandhi61@gmail.com Falguni Patel, E-mail: drfalgunipatel.fp@gmail.com

\begin{abstract}
Background: Breast carcinoma is the leading cause of death with cancer in women. Management of breast lumps can be challenging in resource poor settings. Fine needle aspiration cytology of breast is an important mode of diagnosis and forms a part of triple assessment, which includes FNAC (fine needle aspiration cytology), mammography and clinical examination. Objective: To examine the cytological details in aspirated smears from lumps in the breast, to evaluate the role of FNAC in improving the quality of diagnosis by comparing with histopathological features and to separate malignant lesions that require more radical therapy from benign ones that may be conservatively managed. Methods: A prospective study is carried out on 100 patients with breast lump over a period of one year including 4 bilateral, 49 left sided and 47 right sided lesions at territory hospital, Chandkheda, Ahmedabad, Gujarat. Histopathology examination were obtained in 27 cases. All the aspirates and histopathology slides were stained with H \& E stain. Results: Out of 100 cases of FNAC breast 80 cases were diagnosed as benign and 20 cases were diagnosed as malignant. Histopathological correlation was done on 27 cases and all were confirmed by FNAC. Conclusion: FNAC is a safe, simple, and costeffective outpatient procedure associated with negligible complication. And along with histopathological correlation it increases the diagnostic accuracy. That helps the clinicians for early diagnosis and specific management thus reducing morbidity and mortality.
\end{abstract}

Keywords: Breast lesions, FNAC, Histopathological correlation

\section{Introduction}

Breast cancer is the most frequently diagnosed cancer and the leading cause of death from cancer in women. During the last century much progress has been made for diagnosis, treatment and prevention of breast cancer. Breast cancer survival rates tend to be poorer in developing countries, most likely because of combination of late diagnosis and limited access to timely and appropriate treatment [1]. Increasing incidence of breast cancer in India and the potential curability of disease of detected early has underscored the need for quick and reliable diagnostic method.

FNAC is a quick, reliable and simple diagnostic method. It is one of the important components of triple approach, which has been widely accepted for the preoperative diagnosis of breast lesions which includes clinical examination, imaging and FNAC [2].

Manuscript received: $4^{\text {th }}$ March 2019

Reviewed: $14^{\text {th }}$ March 2019

Author Corrected: $19^{\text {th }}$ March 2019

Accepted for Publication: $22^{\text {nd }}$ March 2019

Pathology Update: Tropical Journal of Pathology \& Microbiology
Over 1,00,000 new breast cancer patients are diagnosed annually in India and according to WHO an estimated 70218 women died due to breast cancer [3].

FNAC in palpable breast masses, either self detected or identified by clinical examination is common. Although most detected masses are benign, every woman presenting with breast mass should be evaluated to exclude or establish the diagnosis of cancer.

The most significant indications for FNAC of breast lesions are evaluation of cystic lesions, diagnosis of recurrent or metastatic diseases, confirmation of locally advanced carcinoma and determination of axillary lymph nodes [4]. Inflammatory breast disease and nonproliferative breast disease do not increase the risk of cancer. Proliferative breast disease without atypia and with atypia confers mild and moderate risk respectively, whereas carcinoma in situ is associated with high risk [5]. 


\section{Materials \& Methods}

Place of study and Type of study: This prospective study is carried out during January 2018 to December 2018 in department of pathology, at Dr. M.K Shah Medical College \& Research centre Chandkheda, Ahmedabad, Gujarat, a tertiary healthcare centre.

Sampling methods and sample collection: After taking history, clinical examination and an informed written consent was taken, the patient was explained the procedure in complete detail.

The procedure was performed without anesthesia by trained pathologist. Lesion fixed with one hand, with quick single motion $22 \mathrm{G}$ needle with $10 \mathrm{ml}$ disposable syringe was inserted in the mass through skin, a change in consistency was felt.

The needle was moved back and forth in the mass in different direction keeping needle in the mass. Aspirated material was taken on labeled glass slides by pushing plunges and smears were prepared. The methanol fixed smears were stained with $\mathrm{H} \& \mathrm{E}$ stain.

The specimen came for histopathology examinations were examined and gross examination was done. Sections were taken from different site. After that slides were made and stained with $\mathrm{H} \& \mathrm{E}$ stain and examined by histopathologist. Criteria for morphological Adequacy: At least six clusters of ductal cells on each smear comprising 10 cells per cluster.

FNAC diagnosis given in following categories:

1. Unsatisfactory/insufficient sample

2. Atypical ductal hyperplasia

\section{Original Research Article}

3. Benign breast lesion: fibroadenoma, fibrocystic disease, benign epithelial hyperplasia, gynecomastia, traumatic, abscess

4. Malignant lesion

\section{Criteria for Malignancy}

The morphological characteristics that were used to distinguish benign from malignant cells are as follows:

1. Abnormal grouping of cells

2. Decreased mutual adhesiveness

3. Changes in the nucleus

4. Increased/abnormal mitoses

5. Variation in size and shape of cells

6. Abnormal cytoplasmic inclusions

The clinical details were obtained from cytology and histopathology requisition forms accompanying the specimen.

The Inclusion criteria: All age group of patients, both sexes presented with breast lump in surgical OPD at Dr. M.K Shah Medical College \& Research centre, Chandkheda for FNAC with or without histopathological confirmation.

The exclusion criteria: Patients who were not willing for the procedure.

The study was approved by ethical committee.

Statistical analysis: The obtained parameters were evaluated using descriptive statistical analysis. Statistical analyses were performed using Microsoft Office Excel 2010 software.

\section{Results}

Table-1: FNAC results age wise Malignant and Benign.

\begin{tabular}{|c|c|c|c|}
\hline Age group (years) & Benign cases & Malignant cases & Total no. cases \\
\hline $10-20$ & 11 & 0 & 11 \\
\hline $21-30$ & 26 & 01 & 27 \\
\hline $31-40$ & 20 & 04 & 24 \\
\hline $41-50$ & 13 & 03 & 16 \\
\hline $51-60$ & 08 & 05 & 08 \\
\hline $61-70$ & 01 & 07 & 00 \\
\hline $71-80$ & 00 & 00 & 01 \\
\hline $81-90$ & 01 & 00 & 100 \\
\hline
\end{tabular}

The study documented the fact that benign lesions were the most common lesion in young females in age group of 21-30 years. Malignant lesions were common in $5^{\text {th }}$ and $6^{\text {th }}$ decades of life, among which the infiltrating ductal carcinoma was the commonest lesion. 


\section{Original Research Article}

Right sided lesion was seen in 47 cases, left sided lesion in 49 cases and bilateral lesion in 5 cases.

Table-2: Distribution of cytological diagnosis according to categories.

\begin{tabular}{|c|c|}
\hline Diagnostic categories & No. of cases \\
\hline Unsatisfactory/insufficient & 01 \\
\hline Atypical hyperplasia & 01 \\
\hline Benign breast lesions & 78 \\
\hline Malignant lesions & 20 \\
\hline
\end{tabular}

Out of 100 cases $80 \%$ cases were diagnosed benign and $20 \%$ cases were malignant lesion.

Table-3: Cytological diagnosis of breast lesion FNAC.

\begin{tabular}{|c|c|}
\hline Diagnosis & No. of cases \\
\hline Fibroadenoma & 45 \\
\hline Benign breast lesion & 05 \\
\hline Fibrocystic disease & 15 \\
\hline Benign epithelial hyperplasia & 01 \\
\hline Gynecomastia & 04 \\
\hline Traumatic & 03 \\
\hline Abscess & 05 \\
\hline Non sufficient & 01 \\
\hline Atypical hyperplasia & 01 \\
\hline Malignant lesion Ductal carcinoma & 20 \\
\hline Total & $\mathbf{1 0 0}$ \\
\hline
\end{tabular}

Among all cytopathological diagnosis of lesions, fibroadenoma were most common benign findings in breast lump. Ductal carcinoma were common in all malignant lesions of breast \& 15 cases were diagnosed as fibrocystic disease.

Out of 100 cases histopathological correlation were done in 27 cases. And out of 27 cases 25 confirmed benign in FNAC as well as in histopathological evaluation. Two malignant cases were also confirmed in cytological diagnosis and histopathological examination.

\section{Discussion}

Now a days, FNAC is a common diagnostic modality practiced all over the world with encouraging results. This is usually done as the first line investigation and it may lead to a definite treatment if an unequivocal diagnosis is achieved.

FNAC is not only useful in diagnosis and further planning of treatment without need for biopsy, but also helpful in prognostification of the tumor factors such as nuclear grading, mitotic index, hormone receptor status and DNA contents [6].

Accurate diagnosis of breast tumors can help and avoid unnecessary surgical procedures and plan correct treatment options. Early screening and diagnosis of breast lesions and categorization into different groups of breast pathology can be helpful in accurate management of breast lesions [7].
Recently, cytopuncture or Non aspiration cytology has gained popularity because of its ease of use, interpretation of results, its safety and claims that it yields specimen of superior diagnostic accuracy [8].

The results of our study showed FNAC of breast lump to be a reliable method to diagnose breast lump with high accuracy. Different studies have shown that the most common lesions are benign, that also observed in our study. In present study, 100 aspiration were performed during January 2018 to December 2018. Out of 100 cases, 27 cases were followed by histopathology confirmation.

Among them 25 benign cases and 2 malignant cases were confirmed by FNAC as well as by histopathology examination. Cytology and histopathology correlation observed in our study. Present study observed the common age group for FNAC was 21-30 years and that 
also observed by Sreedevi CH et al [9] and Sahil I et al [2] and Begun farida [10] et al. In our study youngest patient was 18 years old and oldest patient was 82 years old, which also correlated with Pinto et al study [11].

Various authors proposed different reporting protocols in classifying the breast lesions. Feichter analyzed, 472 aspirations and classified the lesions into four categories; benign,suspicious, malignant and inadequate [12].

In this study, the lesions were classified into four categories:

1. Unsatisfactory/Insufficient

2. Atypical ductal hyperplasia

3. Benign breast lesion: fibroadenoma, fibrocystic disease, benign epithelial hyperplasia, gynecomastia, traumatic, abscess

4. Malignant lesion

In present study, cytological diagnosis of 100 aspirations were reviewed and lesions were classified into four diagnostic classes revealing 01 unsatisfactory, 01 atypical hyperplasia, 78 benign and 20 malignant. In the series of benign breast lesions, fibroadenoma constituted the largest disease group with maximum incidence in the third decade which also observed in Sonali Saraf et al [13], Sreedevi et al [9], Dr. A. Savangan [3], Sahil I et al [2], Pinto et al [11], Chauhan $\mathrm{N}$ et al[14], Gupta $\mathrm{R}$ [15], Begun Farida et al[10] and Bhagat $R$ et al [16]. But in other studies like Ishita $P$ et al [17], Swapan et al [18] and Sushma et al [19] fibrocystic change was the commonest benign lesion.

In our study left sided lesions were more than right side lesions which also observed in Ambedkar R et al [20] study Meena et al [6], Reddy DG et al [21] and CleggLamptey J et al [22], but Sreedevi et al [9] study showed right sided lesions more than left sided lesions.

Among malignant lesions, ductal cell carcinoma was the most common, which coincide with the many authors $[18,19,20]$. The difference was noted in the incidence of malignant and benign lesions in various studies, which may be explained on basis of variables like duration of study period, number of cases studied, age group of patients etc.

The main reason for inadequate smears were poor cellularity due to lack of experience in performing aspiration technique or getting the material on to the slide. Aspiration of ill-defined fibrocystic lesions, fibroadenoma with hyalinization and deep locations of tumors also contributed to the conclusive diagnosis.

\section{Original Research Article}

\section{Conclusion}

The FNAC of breast is cost effective, safe and highly reliable method for diagnosis of breast lump preoperatively to avoid undue surgery and inconvenience during biopsy.

FNAC of breast should be OPD investigation, and you can use same aspirate for molecular study also. The inadequate smears were very few which were mostly because of small size lesion, extensive fibrosis, edema, cyst or geographic miss by needle.

The procedure has a high sensitivity and specificity with a high predictive value for malignancy.

\section{What this study adds to existing knowledge?}

This study helps to differentiate benign, inflammatory and malignant lesions of breast without any surgical intervention or in setups where proper surgical facilities are unavailable. So the early treatment of patients with malignancy can be done on time.

\section{Author Contributions}

All Authors had equally contributed in every part of research like manuscript writing, data collection and statistical analysis.

Funding: Nil; Conflict of Interest: None initiated Permission from IRB: Yes

\section{References}

1. Jemal A, Bray F, Center MM, et al. Global cancer statistics. CA Cancer J Clin. 2011 Mar-Apr;61(2):6990. doi: 10.3322/caac.20107. Epub 2011 Feb 4.

2. Sahil I. panjuani, Biren J. Parikh et al. Utility of fine needle Aspiration cytology in the evaluation of breast lesions. Jou. Of clinical diag. research 2013 Dec, vol. 7 (12): 2777-2779.

3. A. Sarangan, R. Geetha et al. Study of Histopathological correlation of breast mass with radiological and cytological findings, IOSR-JDMS. 2017 March, vol.16 (3). ver.IX, PP01-07.

4. Ljiljana Vuckovic, Nebojsa crnogorac et al. Comparison of cytological categories a typical (C3) and suspected (C4) with histopathological diagnosis of breast lesions. JBUON 2018;23(2):366-371.

5. Tiwari M. Role of fine needle aspiration cytology in diagnosis of breast lumps. Kathmandu Univ Med J (KUMJ). 2007 Apr-Jun;5(2):215-7. 
6. Meena SP, Hemrajani DK, Joshi N. A comparative and evaluative study of cytological and histological grading system profile in malignant neoplasm of breast- an important prognostic factor. Indian J Pathol Microbiol. 2006 Apr; 49(2):199-202.

7. Rahman MZ, Sikder AM, Nabi SR. Diagnosis of breast lump by fine needle aspiration cytology and mammography. Mymensingh Med J. 2011 Oct; 20 (4): 658-64.

8. Koirala S. Comparative study of aspiration and non aspiration cytology of palpable breast lumps and correlation with histopathology. Journal of pathology of Nepal. 2014;4:639-43.

9. Sreedevi $\mathrm{CH}, \mathrm{K}$ Pushpalatha Correlative study of FNAC and histopathology for breast lesions. Trop J Path Micro 2016;2(3):206-211.

10. Farida Begum, P. Ravi Kumar. Diagnostic correlation of palpable breast masses by cytology and histopathology: A prospective study. IAIM,2018; 5(11): 44-49.

11. Pinto RG, Kulwant S. A statistical analysis of fine needle aspiration biopsies in palpable benign (neoplastic and non-neoplastic) breast lesions. J cytol 2004; $21: 64-7$.

12. Feichter GE, Haberthür F, Gobat S, et al. Breast cytology. Statistical analysis and cytohistologic correlations. Acta Cytol. 1997 Mar-Apr;41(2):327-32. DOI: $10.1159 / 000332520$

13. Sonali Saraf, Manisha Khare, Alka kalgutkar. Fine Needle Aspiration Cytology of Breast Lumps- a correlation with histopathology diagnosis.IJPO JanuaryMarch 2016;3(1);103-106

\section{Original Research Article}

14. Chauhan N, Pathak V.P, Harsh M, Saini S. Cytohistopathological correlation in palpable Breast lesions. Indian Medical Gazette. Dec 2012, 473-478

15. Gupta R, Dewan D, Kumar D, Sharma R. Utility of fine-needle aspiration cytology as a screening tool in diagnosis of breast lumps. ISJ 2017;4(4)2349-3305.

16. Bhagat R, Bal MS, Bodal VK, Suri AK, Jindal K. Cytological study of palpable breast lumps with their histological correlation. Int J Med and Detal Sci 2013;2 (2) : 128-136.

17. Ishita P, Singh PK. Cytomorphologic study of palpable breast lesions and histopathologic correlation. J Cytol 2003;20:129-32.

18. Swapan KR, Ranjana B. FNAC of breast with reference to topography and nuclear grading in malignant lesions. J Cytol 2002;19:187-92

19. Yalavarthi S, Tanikella R, Prabhala S, TAllam US. Histopathological and cytological correlation of tumors of breast. Med J D Y Patil Univ 2014;7:326-31

20. Ambedkar $\mathrm{R}$ et al. Cytological evaluation of benign breast lesions with histopathological correlation. IJPO January- March 2016;3(1);7-10.

21. Reddy DG, Reddy CRR. Carcinoma of the breast, its incidence and histological variants among South Indians. Indian J Med Sci 1958;12:228-34.

22. Clegg-Lamptey J, Hodasi W. A study of breast cancer in korle bu teaching hospital: assessing the impact of health education. Ghana Med J. 2007 Jun; 41(2):72-7.

\section{How to cite this article?}

Patel F.T, Shah B.A, Parikh N.R, Gonsai R.N. Cytological evaluation of breast lesions with histopathological correlation in patients present with breast lump. Trop J Path Micro 2019;5(3):132-136.doi:10.17511/jopm.2019.i03.04. 